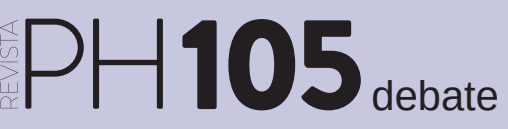

Interpretación y gestión del patrimonio en los espacios del turismo oscuro

coordinan Óscar Navajas Corral y Maribel Rodríguez Achútegui

\title{
Las Rutas de Guerra en la España Nacional: patrimonio, turismo y propaganda política
}

\author{
Saida Palou Rubio | Institut Català de Recerca en Patrimoni Cultural \\ URL de la contribución <www.iaph.es/revistaph/index.php/revistaph/article/view/5036>
}

El turismo en zonas de guerra incentivado oficialmente y financiado por instituciones y gobiernos constituye una modalidad turística excepcional. Conocemos algunos casos puntuales en la historia. Sus fines no son exclusivamente económicos, sino, sobre todo, políticos e ideológicos. Las motivaciones que impulsan la movilidad de los visitantes no son el ocio, el goce y el placer, sino el reconocimiento de una causa política y el interés por las contingencias que implica. Los paisajes y patrimonios que se muestran en estos escenarios son deliberadamente seleccionados; el objeto en sí mismo (el patrimonio material, por así decirlo) será importante, puesto que en él se concentrará la atención de sus visitantes, pero, por encima de todo, lo más relevante será la narrativa y la memoria que se construye a su propósito. La capacidad del patrimonio para evocar una historia y valores depende de las intenciones de los agentes que lo presentan. En un contexto de guerra activa, con paisajes efímeros y peligrosos, la fragilidad y destrucción de los bienes culturales se convierte en centro de atención. En consecuencia, la mirada turística sedimentará y participará en un proceso de valorización patrimonial y legitimización política. Esas fueron las intenciones de las Rutas de Guerra puestas en marcha en la España Nacional en los años 1938 y 1939, una modalidad de turismo político cuyo análisis aporta claves sobre las bases técnicas de manipulación de la realidad y del diferente entendimiento cultural y paisajístico de un territorio en guerra (Brandis y Río 2016).

Durante la Guerra Civil española la promoción del turismo queda sometida a los intereses políticos de los dos bandos en conflicto, que utilizarán sus servicios a diferente escala para las respectivas causas (Moreno Garrido y Villaverde 2019). Así, conviven dos prácticas turísticas con una fuerte orientación política y propagandística (Río Lafuente 2016). Los bandos enfrentados promueven un turismo político, una forma de turismo que nada tiene que ver con el ocio y el recreo, ni apenas con fines económicos, puesto que su propósito tiene que ver con los valores y causas de quienes lo impulsan. Nos fijamos en el caso del gobierno sublevado, que en 1938 impulsará las Rutas de Guerra, consideradas el único ejemplo de la historia en que un gobierno organiza rutas turísticas comerciales guiadas a una zona de guerra activa (Brandis y Río 2016). Arte, turismo y tragedia formarán parte de una gran campaña de propaganda política sin precedentes realizada por los franquistas (Correyero Ruiz 2001).

El mes de enero de 1938 se crea en Burgos el Servicio Nacional de Turismo (SNT). Luis Antonio Bolín Bidwell, abogado, periodista, franquista convencido y consumado propagandista (Larrinaga Rodríguez 2019), estará al frente del SNT, adscrito al Ministerio de Interior. Bolín tenía contactos con grupos políticos afines ingleses y experiencia técnica en el campo del turismo, el periodismo y la propaganda (Brandis y Río 2016), de modo que pudo organizar y poner en marcha las denominadas Rutas de Guerra, itinerarios por los monumentos y lugares de guerra con aras de legitimar el gobierno de Franco. Se planificaron un total de cuatro rutas: la del Norte, la de Aragón, la del Centro y la de Andalucía. Su principal misión era la de difundir la versión nacional de la sublevación militar justificada como necesaria para la salvación del país (Concejal López 2014).

El 1 de julio de 1938 se inauguran los dos itinerarios de la Ruta de Guerra del Norte con un recorrido de 1.000 y 1.500 kilómetros cada uno. Así, el norte se convierte en 


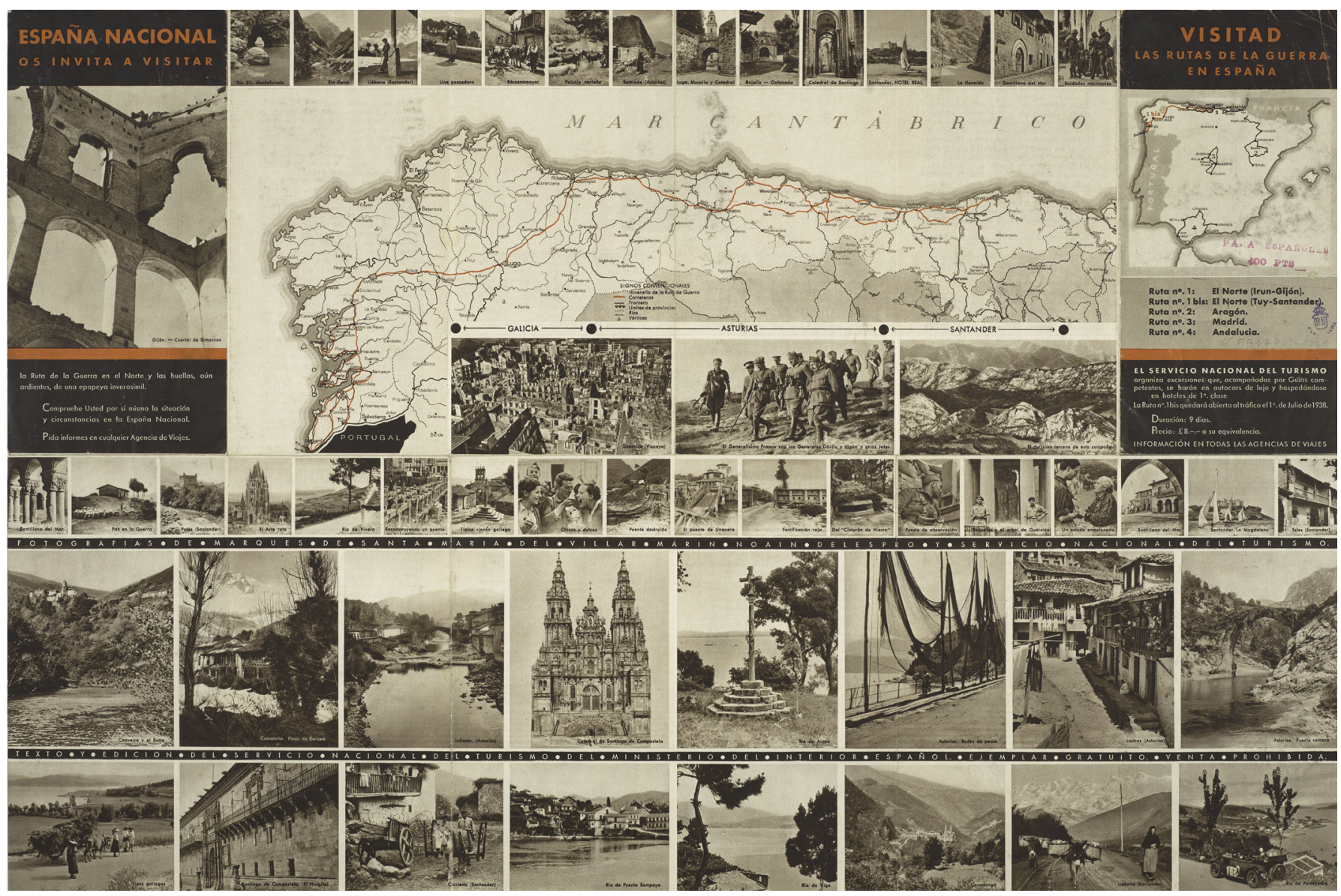

Mapa de las Rutas Turísticas de Guerra, 1938 Servicio Nacional de Turismo | fuente Biblioteca Nacional

el escaparate de una gran campaña en la que el turismo sirvió como pretexto para la evocación y apología de los fundamentos predicados por el régimen franquista. Los circuitos iban acompañados de intérpretes especializados que proporcionaban información de los lugares y el curso de la guerra. Todos los guías pertenecían a la Falange (Correyero Ruiz 2001). Se editó material promocional (folletos y carteles) que se exhibieron en los escaparates de las agencias especializadas. Las fotografías propagandísticas de la contienda mostraban la reconstrucción de puentes y edificios y la alegría del pueblo al paso de las tropas nacionales, así como fotos del general Franco. Por lo tanto, mostraban una visión positiva de un territorio en guerra. Consta que las agencias extranjeras mostraron interés en dichas rutas. Los usuarios quedaban sujetos a una normativa muy estricta, entre las cuales no poder entrar ni sacar máquinas fotográficas del país, si bien les era permitido comprar fotografías. También quedaba prohibido entrar y sacar mapas de la España Nacional. La Ruta de Andalucía recibió varias quejas por el calor y el mal estado de las carreteras (Concejal López 2014). A los 18 meses de la puesta en marcha de las rutas se habían recorrido 250.000 kilómetros, transportado a 8.060 pasajeros y abonado facturas a hoteles por valor de 461.251 pesetas. El estado también tuvo beneficios económicos, aparte de los políticos (Larrinaga Rodríguez 2019). En 1939 el SNT se recalificó como Dirección General de Turismo y la sede de Burgos pasó a Madrid. En 1940 la Rutas de Guerra se convirtieron en Rutas Nacionales, y sus fines pasaron 
a debate Interpretación y gestión del patrimonio en los espacios del turismo oscuro

| coordinan Óscar Navajas Corral y Maribel Rodríguez Achútegui

a ser fundamentalmente turísticos, o sea, relacionados con el ocio.

¿Fueron las Rutas de Guerra una modalidad de turismo oscuro, puesto que transitaban por lugares de guerra, destrucción y muerte? ¿Podríamos imponer esta u otras categorías contemporáneas a aquellos acontecimientos? Atribuir conceptos del presente a hechos del pasado implica el peligro de identificar una realidad con unas lógicas que no eran las propias. Lo que buscaban los promotores de las Rutas de Guerra era generar una opinión, un apoyo, la adhesión a una causa y el odio a otra. Se trataba de actuar en los sentimientos e ideologías de los visitantes extranjeros. Los lugares que se visitaban eran testimonios de un presente trágico y a su vez pruebas de una victoria y recuperación. Fueron, entonces, las Rutas de Guerra una forma de hacer política mediante la exposición del patrimonio, y fueron, también, una forma de utilizar el turismo (una práctica nacida de la modernidad e impulsada por el liberalismo) por parte de un gobierno fascista. El patrimonio fue un pretexto y el turismo un instrumento útil para afianzar la causa del gobierno sublevado, a saber: un instrumento de política exterior.

\section{BIBLIOGRAFÍA}

- Brandis, D. y Río, M.I. del (2016) Turismo y paisaje durante la Guerra Civil Española, 1936-1939. Scripta Nova. Revista Electrónica de Geografía y Ciencias Sociales, vol. 20, n. ${ }^{\circ}$ 530, pp. Disponible en: https://revistes.ub.edu/index.php/ ScriptaNova/article/view/530 [Consulta: 10/11/2021]

- Concejal López, E. (2014) Las Rutas de Guerra del Servicio Nacional de Turismo (1938-1939). En: Miguel Arroyo, C. y Ríos Reviejo M.T. (coord.) Visite España: La memoria rescatada. Madrid: Ministerio de Cultura, Subdirección General de Publicaciones, Información y Documentación, pp. 258-273

- Correyero Ruiz, B. (2001) Las rutas de guerra y los periodistas portugueses. Historia y comunicación social, vol. 6 , pp. 123-134. Disponible en: https://revistas.ucm.es/index.php/ HICS/article/view/HICS0101110123A [Consulta: 10/11/2021]

- Larrinaga Rodríguez, C. (2019) El impacto de la Guerra Civil en el sector turístico. En: Fernández Paradas, M. y Larrinaga Rodríguez, C. (coord) El impacto de la Guerra Civil española en el sector terciario. Granada: Editorial Comares, pp. 153-171

- Moreno Garrido, A. y Villaverde, J. (2019) De un sol a otro. Turismo e imagen exterior española (1914-1984). Ayer, vol. 114, pp. 95-121. Disponible en: https://www.revistaayer.com/ articulo/1352 [Consulta: 10/11/2021]

- Río Lafuente, M.I. del (2016) Cultura y paisaje en la política turística del primer franquismo (1939-1956). Estudios geográficos, vol. 77, n. $^{\circ}$ 281, pp. 443-467. Disponible en: https://estudiosgeograficos.revistas.csic.es/index.php/ estudiosgeograficos/article/view/491 [Consulta: 10/11/2021] 